\title{
Electroflotation of ultrafine chalcopyrite particles with sodium oleate collector
}

\author{
Fidele Makuei, Bogale Tadesse, Boris Albijanic* and Richard Browner \\ Department of Mining Engineering and Metallurgical Engineering, Western Australian \\ School of Mines, Curtin University, Egan St, Kalgoorlie, WA 6430, Australia \\ bogale.tadesse@curtin.edu.au
}

\begin{abstract}
The electroflotation behaviour of ultrafine chalcopyrite particles was investigated using a mechanically agitated cell. The use of sodium oleate as collector proved effective in the flotation of particles of average size of $5 \mu \mathrm{m}$. The results showed that chalcopyrite recovery increases with increasing pulp $\mathrm{pH}$, and current density, but decreases with increasing pulp density. The successful flotation of chalcopyrite with oleate might be attributed to its electrochemical surface oxidation, resulting in the formation of cupric and ferric oxide species. Chemisorption of oleate ions onto oxidized chalcopyrite surface is suggested to be the main cause for the reasonable chalcopyrite recovery.
\end{abstract}

Key words: Electroflotation; Chalcopyrite; Ultrafine particles; Oleate; Microbubbles

\section{Introduction}

Particle size of $10 \mu \mathrm{m}$ is considered as the critical size below which both flotation selectivity and recovery decline sharply (Trahar and Warren, 1976). The majority of highly liberated fine and ultrafine valuable minerals are lost to tailings during conventional mechanical flotation. This is undesirable particularly in the processing of finely disseminated complex and refractory ores where there is a requirement for fine grinding in order to liberate the valuable minerals. The poor floatability of fine and ultrafine minerals has been attributed to the inherent low probability of collision between small particles and large bubbles existing in conventional flotation cells (Trahar and Warren, 1976). The bubble-particle collision efficiency may be increased by decreasing the bubble size, and thus increasing flotation kinetics and recovery of fine mineral particles (Ahmed and Jameson, 1985). 
Several flotation techniques that make use of fine bubbles have been developed to increase the bubble-particle collision efficiency. These include dissolved air flotation (Matis et al., 1993), electroflotation (Montes-Atenas et al., 2010) and turbulent microflotation (Rulyov, 2001). In electroflotation, bubbles are generated by the electrolytic breakdown of water to produce oxygen and hydrogen gases at the anode and cathode, respectively. This process leads to the formation of fine hydrogen and oxygen bubbles with mean dimensions varying from 15 - 105 $\mu \mathrm{m}$ based on the condition of electrolysis (Jimenez et al., 2010; Sarkar et al., 2010).

Electroflotation is particularly applicable in fine and ultrafine particle flotation because the bubbles size and gas volume can be controlled by varying the current density, pulp $\mathrm{pH}$ and/or electrode materials (Bhaskar and Khangaonkar, 1982). Another advantage is that the electrolytic gases in electroflotation are more active than sparged gases (Llerena et al., 1996).

Electroflotation has been used for the recovery of fine and ultrafine mineral particles such as chalcopyrite (Bhaskar and Khangaonkar, 1982), sphalerite (Llerena et al., 1996), pyrite (Kydros et al., 1994) and cassiterite (Qin et al., 2012). In the majority of these studies, a modified Hallimond tube apparatus with separate flotation chamber and electrolysis section was used (Bhaskar and Khangaonkar, 1982; Matis et al., 1993; Llerena et al., 1996). This technical note aims to investigate the flotation behaviour of ultrafine chalcopyrite particles using a bench scale mechanically agitated electroflotation cell rather than a Hallimond tube. The mechanism of chalcopyrite recovery by electroflotation in the presence of oleate will be discussed.

\section{Experimental}

\subsection{Sample preparation}

Chalcopyrite mineral sample with purity of $95 \%$ as confirmed by using an X-ray diffractometer (XRD) was used in this study. The $80 \%$ passing size for the electroflotation feed used was 5.2 $\mu \mathrm{m}$. The feed sample was considered to be in the ultrafine size range because about $90 \%$ of the particles are $<20 \mu \mathrm{m}$ in diameter.

\subsection{Reagents}

Sodium oleate (Sigma-Aldrich Pty Ltd) was used as collector, Methyl Isobutyl Carbinol (MIBC) from Orica Australia was used as frother, sodium hydroxide (Rowe Scientific Pty Ltd) and hydrochloric acid (Chem-Supply Pty Ltd) were used to adjust the $\mathrm{pH}$ of the pulp. To 
enhance the conductivity of the pulp, $0.5 \% \mathrm{w} / \mathrm{v}$ sodium sulfate (Chem-Supply Pty Ltd) concentration was maintained. All reagents were of analytical grade. Double distilled water with a resistivity of $18.2 \mathrm{M} \Omega$ was used for preparation of all solutions and pulp.

\subsection{Flotation tests}

A bench top $600 \mathrm{ml}$ acrylic electroflotation cell with a stainless steel plate cathode and a lead plate anode $1 \mathrm{~cm}$ apart and both with surface area of $5.7 \times 10^{-4} \mathrm{~m}^{2}$ was used in this study. The electrodes were connected to a DC power supply (Advantek, PS3610) for the generation of bubbles by water electrolysis. A cell voltage of $>1.3 \mathrm{~V}$ vs. SHE was applied to generate hydrogen and oxygen gases in the cell. An overhead stirrer (IKA labortechnik, RW 20) was used to achieve mixing of the pulp in the cell. Fine chalcopyrite sample was added into $0.5 \%$ w/v sodium sulfate electrolyte solution to achieve desired pulp density of solids. The pulp $\mathrm{pH}$ was adjusted, the collector and the frother (MIBC), and the pulp was conditioned for 10 mins. The power supply was turned on and the applied current was adjusted to achieve the required current density. The electroflotation process was allowed to proceed for 15 mins while the froth was continuously collected from the top of the cell.

\section{Results and discussion}

Sulfhydryl collectors such as xanthates were found to be unsuitable in rendering chalcopyrite surfaces hydrophobic in electroflotation system used in this present study. The flotation recovery of chalcopyrite was less than $5 \%$ when sodium ethyl xanthate was used as collector. This is probably due to the fact that the anodic potential applied for bubble generation leads to the oxidation of chemisorbed copper (I) xanthate through the following reaction (Woods et al., 1990):

$2 \mathrm{CuX}+2 \mathrm{H}_{2} \mathrm{O} \rightarrow 2 \mathrm{CuO}+\mathrm{X}_{2}+4 \mathrm{H}^{+}+4 e^{-}$

At anodic potentials, chalcopyrite is expected to undergo oxidation, forming iron oxides on its surface. Given that sodium oleate collector is effective in the recovery of iron oxides (JosephSoly et al., 2015), this collector was chosen to investigate the recovery of chalcopyrite by electroflotation. 


\subsection{Effect of pulp pH on chalcopyrite recovery}

The effect of pulp $\mathrm{pH}$ on chalcopyrite electroflotation recovery was investigated in a pulp of pH 5 - 12. As can be seen from Fig. 1, for the sodium oleate concentrations considered in this study, chalcopyrite recovery generally increases with increasing pulp $\mathrm{pH}$. The precipitation of ferric oxide/hydroxide species on chalcopyrite at higher pulp $\mathrm{pH}$ conditions followed by its chemical interaction between oleate appears to be responsible for this observation. The proposed mechanism of action of oleate during chalcopyrite electroflotation is discussed in section 3.4 .

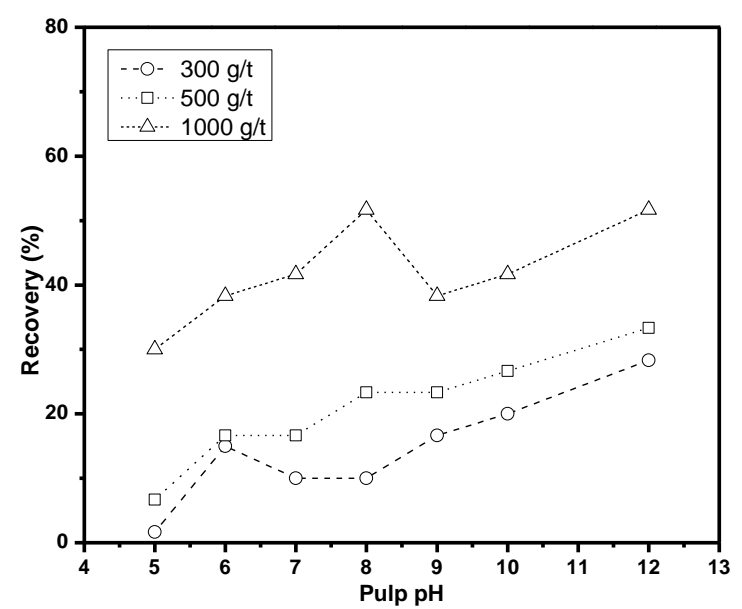

Fig. 1. Effect of pulp $\mathrm{pH}$ on the recovery of chalcopyrite at different sodium oleate concentrations, and current density of $500 \mathrm{~A} / \mathrm{m}^{2}$.

\subsection{Effect of pulp density and current density}

The effect of pulp density (\% solid) on chalcopyrite recovery was investigated at various current densities. As shown in Fig. 2, chalcopyrite recovery increases with increasing current density for pulp density range considered in this study. A large number of bubbles are generated at higher current densities as compared with lower current densities (Jimenez et al., 2010). Thus, the increase in chalcopyrite recovery with increasing current density observed in this study was attributed to higher aeration rate at higher current densities. The effect of air flow rate on flotation kinetics is well documented (Laplante et al., 1983). However, chalcopyrite recovery was found to decrease as pulp density increased from 5\% to 20\%. The highest recovery achieved was $60 \%$ at $5 \%$ solids. At $10 \%$ and $20 \%$ solids, the highest recoveries were $39 \%$ and $19 \%$, respectively. These observations suggest that high pulp density causes a higher degree of bubble surface area overloading with ultrafine particles. The mineralised fine bubbles would be too heavy to float, which then leads to reduction in mineral recovery. 


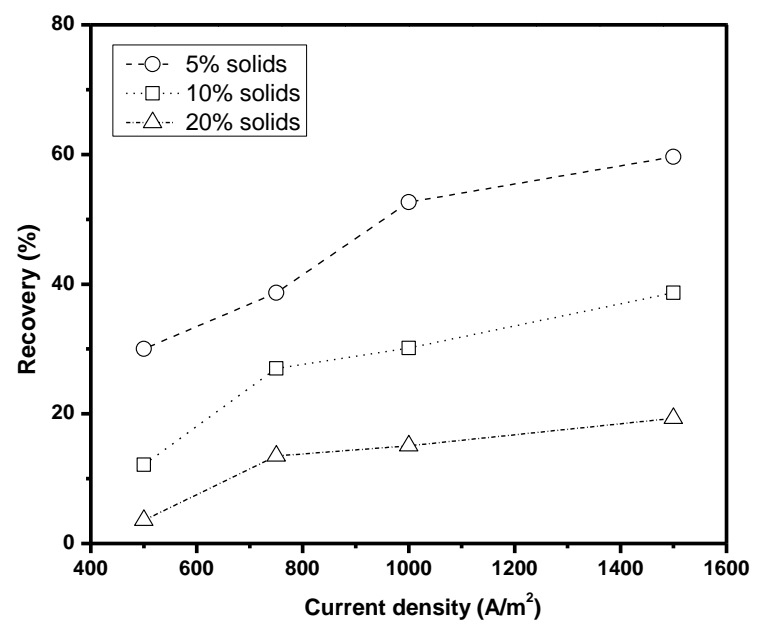

Fig. 2. Effect of current density and pulp density (\% solids) on recovery of chalcopyrite at pH 8 and in the presence of $1000 \mathrm{~g} / \mathrm{t}$ of sodium oleate.

\subsection{Zeta potential of chalcopyrite}

The zeta potential of chalcopyrite was investigated in water and in $0.5 \% \mathrm{w} / \mathrm{v} \mathrm{Na} \mathrm{SO}_{4}$ electrolyte before and after electrolysis in order to quantify the changes in surface charge of particles. As shown in Fig. 3, the zeta potential of chalcopyrite in water becomes more negative with increasing pulp $\mathrm{pH}$ due to adsorbed $\mathrm{OH}^{-}$ions. By contrast, the zeta potential of chalcopyrite in $0.5 \% \mathrm{w} / \mathrm{v}$ sodium sulphate did not change significantly with increasing $\mathrm{pH}$. This may be due to the dominant adsorption of multivalent sulphate ions on the surface of chalcopyrite, stabilizing zeta potential of chalcopyrite. The zeta potential of chalcopyrite in $0.5 \% \mathrm{w} / \mathrm{v}$ sodium sulfate was found to be slightly more positive after electrolysis in comparison with that prior to electrolysis. Considering that chalcopyrite surface in $0.5 \% \mathrm{w} / \mathrm{v}$ sodium sulfate and oleate ions are negatively charged, physisorption is not expected to be responsible for successful chalcopyrite recovery as seen in Figs 1-2. Thus, a chemisorption mechanism was suggested for the adsorption of oleate on chalcopyrite surfaces. The chemisorption mechanism will be discussed in the following section. 


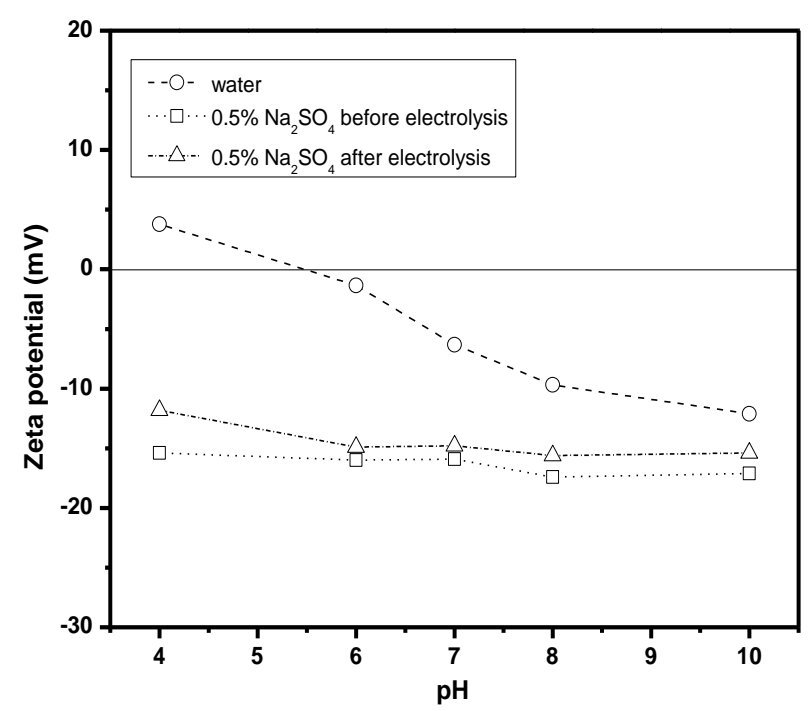

Fig. 3. Zeta potentials of chalcopyrite in water, and in $0.5 \% \mathrm{w} / \mathrm{v}$ sodium sulfate before electrolysis and after electrolysis time of 10 mins at current density of $500 \mathrm{~A} / \mathrm{m}^{2}$.

\subsection{Suggested mechanism for chalcopyrite electroflotation with sodium oleate}

During electroflotation, chalcopyrite is electrochemically oxidized into a number of species in alkaline conditions according to Eqs. 2 and 3 and forms a thin layer of $\mathrm{Cu}(\mathrm{OH})_{2}, \mathrm{Fe}(\mathrm{OH})_{3}, \mathrm{CuO}$ and $\mathrm{Fe}_{2} \mathrm{O}_{3}$ on its surface (Yin et al., 2000).

$$
\begin{aligned}
& \mathrm{CuFeS}_{2}+5 \mathrm{OH}^{-} \rightarrow \mathrm{Cu}(\mathrm{OH})_{2}+\mathrm{Fe}(\mathrm{OH})_{3}+2 \mathrm{~S}+5 e^{-} \\
& 2 \mathrm{CuFeS}_{2}+10 \mathrm{OH}^{-} \rightarrow 2 \mathrm{CuO}+\mathrm{Fe}_{2} \mathrm{O}_{3}+5 \mathrm{H}_{2} \mathrm{O}+4 \mathrm{~S}+10 e^{-}
\end{aligned}
$$

The oxidation of chalcopyrite may also result in a metal-deficient sulphide lattice or metal polysulfide species because of iron and copper leaching (Fairthorne et al., 1997). The various copper oxide and iron oxide species resulting from the oxidation of chalcopyrite may be deduced from Eh-pH diagram of $\mathrm{CuFeS}_{2}-\mathrm{H}_{2} \mathrm{O}$ in which the formation of insoluble ferric and cupric oxide/hydroxides species is thermodynamically predicted at high oxidation potentials in both acidic and alkaline conditions (Fairthorne et al., 1997). Similar ferric and cupric oxide/hydroxides species are expected to form in the present study because the oxidation potential applied was $+1.23 \mathrm{~V}$.

The formation of iron oxide/hydroxide passivating layer can facilitate the strong chemical interaction between oleate and oxidized chalcopyrite surface resulted in the flotation recovery observed in this study at pH $5-9$ (Fig. 1). In contrast to this study, the flotation recovery of 
hematite with sodium oleate collector decreases with increasing $\mathrm{pH}$ beyond 9 (Kulkarni and Somasundaran, 1980). To account for this apparent contradiction, the role of other species needs to be considered. For example, copper oxide/hydroxide species such as $\mathrm{CuOH}^{+}$are formed at higher positive potentials and $\mathrm{pH}>9$ as seen in Eq. 4 (Yin et al., 2000).

$\mathrm{Cu}^{2+}+\mathrm{nH}_{2} \mathrm{O} \leftrightarrow \mathrm{Cu}(\mathrm{OH})_{n}^{(2-n)+}+n \mathrm{H}^{+}$

In the presence of sodium oleate, the following reaction with $\mathrm{CuOH}^{+}$is suggested to occur over the $\mathrm{pH}$ range $6-12.5$ (Venkatachalam and Mallikarijunan, 1965):

$\mathrm{CuOH}^{+}+2 \mathrm{OL}^{-} \leftrightarrow \mathrm{Cu}(\mathrm{OL})_{2}+\mathrm{OH}^{-}$

The successful flotation of chalcopyrite was also observed at $\mathrm{pH}>9$ (see Fig. 1) which may be attributed to the formation of copper-oleate species as seen in Eq. 5. Further studies using surface characterization techniques such as XPS are required to confirm the role of ferric and cupric oxide/hydroxide species in electroflotation of chalcopyrite using sodium oleate collector. However, such investigation is beyond the scope of this technical note.

\section{Conclusions}

The electroflotation behaviour of ultrafine chalcopyrite with sodium oleate collector in various pulp $\mathrm{pH}$, pulp densities and current densities was investigated. The increase in current density leads to an increase in the recovery of ultrafine chalcopyrite. The chalcopyrite recovery was higher at lower pulp densities. The electroflotation of chalcopyrite with sodium oleate collector involves the chemisorption of oleate species on copper oxide and iron oxide layers.

\section{Acknowledgements}

The financial assistance of the Department of Mining Engineering and Metallurgical Engineering, Western Australian School of Mines, Curtin University is gratefully acknowledged.

\section{References}

Ahmed, N., Jameson, G.J., 1985. The effect of bubble size on the rate of flotation of fine particles. Int. J. Miner. Process. 14, 195-215. 
Bhaskar, R.G., Khangaonkar, P.R., 1982. Electro-flotation of chalcopyrite fines. Int. J. Miner. Process. 9, 133-143.

Fairthorne, G., Fornasiero, D., Ralston, J., 1997. Effect of oxidation on the collectorless flotation of chalcopyrite. Int. J. Miner. Process. 49, 31-48.

Jimenez, C., Talavera, B., Saez, C., Can'izares, P., Rodrigo, M.A., 2010. Study of the production of hydrogen bubbles at low current densities for electroflotation processes. J. Chem. Technol. Biotechnol. 85, 1368-1373.

Joseph-Soly, S., Quast, K., Connor, J. N., 2015. Effects of Eh and pH on the oleate flotation of iron oxides. Min. Eng. 83, 97-104.

Kulkarni, R.D., Somasundaran, P., 1980. Flotation chemistry of hematite/oleate system. Colloid Surface 1, 387-405.

Kydros, K.A., Gallios, G.P., Matis, K.A., 1994. Electrolytic flotation of pyrite, J. Chem. Tech. Biotechnol. 59, 223-232.

Laplante, A.R., Toguri, J.M., Smith, H.W., 1983. The effect of air flow rate on the kinetics of flotation. Part 1: The transfer of material from the slurry to the froth. Int. J. Miner. Process. $11,203-219$.

Llerena, C., Ho, J.C.K., Piron, D.L., 1996. Effects of pH on electroflotation of sphalerite. Chem. Eng. Commun. 155, 217-228.

Matis, K.A., Gallios, G.P., Kydros, K.A., 1993. Separation of fines by flotation techniques. Sep. Technol. 3, 76-90.

Montes-Atenas, G., Garcia-Garcia, F.J., Mermillod-Blondin, R., Montes, S., 2010. Effect of suspension chemistry onto voltage drop: Application of electro-flotation. Powder Technol. 204, 1-10.

Qin, W., Ren, L., Wang, P., Yang, C., Zhang, Y., 2012. Electro-flotation and collisionattachment mechanism of fine cassiterite. Trans. Nonferrous Met. Soc. China 22, 917924.

Rulyov, N.N., 2001. Turbulent microflotation: theory and experiment. Colloid Surface A: Physicochem. Eng. Aspects 192, 73-91.

Sarkar, M.S.K.A., Evans, G.M., Donneb, S.W., 2010. Bubble size measurement in electroflotation. Miner. Eng. 23, 1058-1065.

Trahar, W.J., Warren, L.J., 1976. The floatability of very fine particles -a review. Int. J. Miner. Process. 3, 103-131.

Venkatachalam, S., Mallikarijunan, R., 1965. Activation and deactivation studies with copper (II) ions on the soap flotation of quartz. J. Appl. Chem. 15, 605-609.

Woods, R., Young, C.A., Yoon, R.H., 1990. Ethyl xanthate chemisorption isotherms and Eh-pH diagrams for the copper/water/xanthate and chalcocite/water/xanthate systems. Int. J. Miner. Process. 30, 17-33.

Yin, Q., Vaughan, D.J., England, K.E.R., Kelsall, G.H., Brandon, N.P., 2000. Surface Oxidation of Chalcopyrite $\left(\mathrm{CuFeS}_{2}\right)$ in Alkaline Solutions. J. Electrochem. Soc. 147, 2945-2951. 